\title{
Assessment of meteorology vs. control measures in the China fine particular matter trend from 2013 to 2019 by an environmental meteorology index
}

\author{
Sunling Gong ${ }^{1}$, Hongli Liu ${ }^{1}$, Bihui Zhang ${ }^{2}$, Jianjun $\mathrm{He}^{1}$, Hengde Zhang ${ }^{2}$, Yaqiang Wang ${ }^{1}$, Shuxiao Wang ${ }^{3}$, \\ Lei Zhang ${ }^{1}$, and Jie Wang ${ }^{4}$ \\ ${ }^{1}$ State Key Laboratory of Severe Weather \& Key Laboratory of Atmospheric Chemistry of CMA, \\ Chinese Academy of Meteorological Sciences, Beijing 100081, China \\ ${ }^{2}$ National Meteorological Center, Beijing 100081, China \\ ${ }^{3}$ School of Environment and State Key Joint Laboratory of Environment Simulation and Pollution Control, \\ Tsinghua University, Beijing 100084, China \\ ${ }^{4}$ Hangzhou YiZhang Technology Co., Ltd., Hangzhou, China
}

Correspondence: Sunling Gong (gongsl@cma.gov.cn) and Hongli Liu (liuhl@cma.gov.cn)

Received: 10 April 2020 - Discussion started: 15 July 2020

Revised: 26 January 2021 - Accepted: 27 January 2021 - Published: 1 March 2021

\begin{abstract}
A framework was developed to quantitatively assess the contribution of meteorology variations to the trend of fine particular matter $\left(\mathrm{PM}_{2.5}\right)$ concentrations and to separate the impacts of meteorology from the control measures in the trend, based upon the Environmental Meteorology Index (EMI). The model-based EMI realistically reflects the role of meteorology in the trend of $\mathrm{PM}_{2.5}$ and is explicitly attributed to three major factors: deposition, vertical accumulation and horizontal transports. Based on the 2013-2019 $\mathrm{PM}_{2.5}$ observation data and re-analysis meteorological data in China, the contributions of meteorology and control measures in nine regions of China were assessed separately by the EMI-based framework. Monitoring network observations show that the $\mathrm{PM}_{2.5}$ concentrations have declined by about $50 \%$ on the national average and by about $35 \%$ to $53 \%$ for various regions. It is found that the nationwide emission control measures were the dominant factor in the declining trend of China $\mathrm{PM}_{2.5}$ concentrations, contributing about $47 \%$ of the $\mathrm{PM}_{2.5}$ decrease from 2013 to 2019 on the national average and $32 \%$ to $52 \%$ for various regions. The meteorology has a variable and sometimes critical contribution to the year-by-year variations of $\mathrm{PM}_{2.5}$ concentrations, $5 \%$ on the annual average and $10 \%-20 \%$ for the fall-winter heavy pollution seasons.
\end{abstract}

\section{Introduction}

Recent observation data from the Ministry of Ecology and Environment of China (MEE) have shown a steady improvement of air quality across the country, especially in particular matter (PM) concentrations (Hou et al., 2019). According to the 2013-2019 China Air Quality Improvement Report issued by the MEE, compared to 2013, the average concentrations of particulate matter with an aerodynamic diameter of less than $2.5 \mu \mathrm{m}\left(\mathrm{PM}_{2.5}\right)$ in 74 major cities of China decreased by more than $50 \%$ in 2019. From scientific and management point of views, a quantitative apportionment of the reasons behind the trend is critical to assess the reduction strategies implemented by the government and to guide future air quality control policy. However, the assessment of the improvements of air quality is a complicated process that involves the quantification of changes in the emission sources, meteorological factors, and other characteristics of the $\mathrm{PM}_{2.5}$ pollution, which are also interacting with each other. In order to separate the relative degree of these factors, a comprehensive analysis, including observational data and model simulation, is needed.

Studies have been done extensively on the impacts of weather systems on air quality. Synoptic and local meteorological conditions have been recognized as influencing the PM concentrations at various scales (Beaver and Palazoglu, 
2006; He et al., 2017a, b; Pearce et al., 2011a, b). For the atmospheric aerosol pollution, the dynamic effect of the downdraft in the "leeward slope" and "weak wind area" of the Qinghai Tibet Plateau in winter is not conducive to the diffusion of air pollution emissions in the urban agglomerations of eastern China (Xu et al., 2015, 2002). The evolution of circulation situation is an important factor driving the change in haze pollution (He et al., 2018). The local circulations, such as mountain and valley wind and urban island circulation, have a significant impact on local pollutant concentration (Chen et al., 2009; Yu et al., 2016). Previous studies also revealed that $\mathrm{PM}_{2.5}$ concentration is significantly correlated with local meteorological elements, such as temperature, humidity, wind speed, and boundary layer height (He et al., 2017b; Bei et al., 2020; Ma et al., 2019; He et al., 2016).

In the Beijing-Tianjin-Hebei (BTH) region, a correlation analysis and principal component regression method (Zhou et al., 2014) was used to identify the major meteorological factors that influenced the API (Air Pollution Index) time series in China from 2001 to 2010, indicating that air pressure, air temperature, precipitation and relative humidity were closely related to air quality with a series of regression formulas. Yet the analysis was assumed to be a relatively unchanged emission whose impacts were not taken into account. On a local scale, an attempt (Zhang et al., 2017) was made to correlate the air pollutant levels with a combination of meteorological factors with the development of the Stable Weather Index (SWI) at the China Meteorological Administration (CMA). The SWI is a composite index which includes the advection, vertical diffusion and humidity and other meteorological factors that are related to the formation of air pollutions in a specific region or city. A higher value of SWI means a weaker diffusion of air pollutants. This index had some success in assessing the meteorological impacts on air pollution, especially calibrated for a specific region, i.e., Beijing. However, when applied to different areas where the emission patterns and meteorological features are different, this index failed to give a universal or comparable indication of meteorological assessment of pollution levels across the nation.

Using the Kolmogorov-Zurbenko (KZ) wave filter method, Bai et al. (2015) separated the API time series into three Chinese cities into short-term, seasonal and long-term components and then used the stepwise regression to set up API baseline and short-term components separately and established linear regression models for meteorological variables of corresponding scales. Consequently, with the long term representing the change in emissions removed from the time series, the meteorological contributions alone were assumed and analyzed, pointing out that unfavorable conditions often lead to an increase by $1-13$ and the favorable conditions to a decrease by 2-6 in the long-term API series, respectively. Though the contributions of emissions and meteorological variations were separated by the research, it was only done by mathematical transformations and far from the reality. The mechanisms behind the variation of the time series were not investigated.

A chemical transport model (CTM) is an ideal tool to carry the task of assessment by taking the meteorology, emissions and processes into consideration altogether. Andersson et al. (2007) used a CTM to study the meteorologically induced inter-annual variability and trends in deposition of sulfur and nitrogen as well as concentrations of surface ozone $\left(\mathrm{O}_{3}\right)$, nitrogen dioxide $\left(\mathrm{NO}_{2}\right)$ and $\mathrm{PM}$ and its constituents over Europe during 1958-2001. It is found that the average European interannual variation, due to meteorological variability, ranges from $3 \%$ for $\mathrm{O}_{3}, 5 \%$ for $\mathrm{NO}_{2}, 9 \%$ for $\mathrm{PM}, 6 \%-9 \%$ for dry deposition, to about $20 \%$ for wet deposition of sulfur and nitrogen. A multi-model assessment of air quality trends with constant anthropogenic emissions was also carried out in Europe (Colette et al., 2011) and found that the magnitude of the emission-driven trend exceeds the natural variability for primary compounds, concluding that emission management strategies have had a significant impact over the past 10 years, hence supporting further emission reduction strategies. Model assessments of air quality trends in various regions and time periods (Wei et al., 2017; Li et al., 2015) in China were also done and yielded some useful results. For the BTH region, $\mathrm{Li}$ et al. (2015) used the Comprehensive Air Quality Model with extensions (CAMx) plus the Particulate Source Apportionment Technology (PSAT) to simulate the contributions of emission changes in various sectors and changes in meteorology conditions for the $\mathrm{PM}_{2.5}$ trend from 2006 to 2013. It was found that the change in source contribution of $\mathrm{PM}_{2.5}$ in Beijing and northern Hebei was dominated by the change in local emissions. However, for Tianjin and central and southern Hebei Province, the change in meteorology conditions was as important as the change in emissions, illustrating the regional difference of impacts by meteorology and emissions. However, the emission changes in the simulations were assumed and did not reflect the real spatio-temporal variations.

There is no surprise that previous studies could not systematically catch the meteorological impacts across the whole nation as the controlling meteorological factors involving the characteristics of plenary boundary layers (PBLs), wind speed and turbulence, temperature and stability, radiation and clouds, underlying surface as well as pollutant emissions vary greatly from region to region. A single index or correlation cannot be applied to the entire nation. Obviously, in order to systematically assess the impacts of meteorology on air pollution, these factors have to be taken into consideration in a framework and be assessed simultaneously. This paper presents a methodology to assess the individual impacts of meteorology and emission changes, based on a modelderived index EMI, i.e., Environmental Meteorology Index, and observational data, providing a comprehensive analysis of the air quality trends in various regions of China, with mechanistic and quantitative attributions of various factors. 


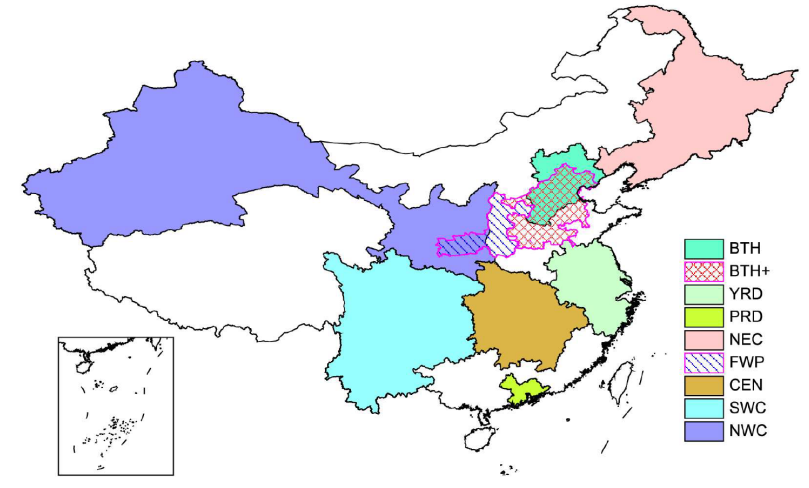

Note: $\underline{\text { BTH}}$ : Beijing, Tianjin and Hebei; $\underline{\text { BTH+: }}$ BJ, TJ + 26 cities; $\underline{\text { YRD: }}$ Shanghai, Jiangsu, Zhejiang and Anhui; PRD: 9 cities in Guangdong; NEC: Heilongjiang, Jilin and Liaoning; FWP: 11 cities in Shanxi, Shannxi and Henan; CEN: Hubei, Hunan and Jiangxi; SWC: Yunnan, Guizhou, Sichuan, Chongqing; NWC: Shannxi, Gansu, Ningxia and Xinjiang

Figure 1. Analysis region separation and definition.

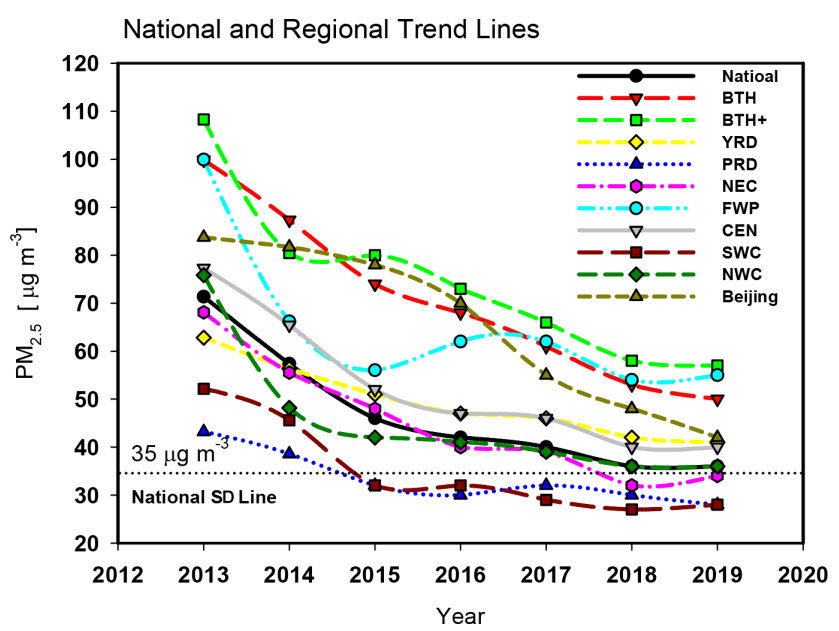

Figure 2. National and regional trend lines of $\mathrm{PM}_{2.5}$ in China from 2013 to 2019.

\section{Methodology}

The assessment is carried out through the combination of observational data and the EMI from model analysis. Since the emission and air quality characteristics vary greatly from region to region in China, the analysis is divided into nine focused regions (Fig. 1). Regional air quality data $\left(\mathrm{PM}_{2.5}\right)$ provides the basis for the trend analysis. Separating the trend contribution from regional emission reduction and meteorological variation entails a framework which is discussed below.

\subsection{Particular matter (PM) observation data}

The observational pollution data of $\mathrm{PM}_{2.5}$ concentrations used in this study were from the monitoring network of the MEE of China (http://english.mee.gov.cn/, last access:
31 December 2020). From 2013 to 2019, the concentrations showed a large change in the country, where most regions saw a declined trend in the annual concentrations. Data show that from 2013 to 2019, the national annual averaged $\mathrm{PM}_{2.5}$ concentrations dropped about $50 \%$ (Fig. 2), where the haze days have been shortened by $21.2 \mathrm{~d}$ from the CMA monitoring data (Table 1), with some regional differences. Regionally, by 2019 , the $\mathrm{PM}_{2.5}$ reduction rate from 2013 ranged from $35 \%$ to $53 \%$. Detailed analysis will be carried out in the Results and discussions section.

It is noted that the $\mathrm{PM}_{2.5}$ mass concentrations by the MEE are now reported under the observation site's actual conditions of temperature and pressure from 1 September 2018, before which the values were reported under the standard state (STP), i.e., $273 \mathrm{~K}$ and $101.325 \mathrm{kPa}$. In order to maintain the consistency of the data series, the $\mathrm{PM}_{2.5}$ concentrations used in this study have all been converted according to the new standard (MEE, 2012) (GB3095-2012) under actual conditions. Research has shown that after the change in reporting standard, the $\mathrm{PM}_{2.5}$ concentration in most cities decreased, and the number of good days to meet the standard increased (Zhang and Rao, 2019).

\subsection{Meteorological data}

Conventional meteorological data can provide qualitative assessment of the contributions of meteorological factors to the changes in air quality. The data used in this study are from 843 national base weather stations of the CMA from 2013 to 2019. The wind speed (WS), day with small wind (DSW), relative humidity $(\mathrm{RH})$ and haze days are used to analyze the pollution meteorological conditions. When the daily average wind speed is less than $2 \mathrm{~m} \mathrm{~s}^{-1}$, a DSW is defined. Since the haze formation is always related to stable meteorological conditions and high aerosol mass loading, haze observation from the CMA is also used to analyze the haze trends and the impact of air quality on visibility. A haze day is defined with daily averaged visibility less than $10 \mathrm{~km}$ and relative humidity less than $85 \%$ (Wu et al., 2014), excluding days of low visibility due to precipitation, blowing snow, blowing sand, floating dust, sandstorms and smoke.

The 2019 national annual averaged WS increased by $4.5 \%$, DSW dropped by $15.1 \%$, and RH decreased by $3.9 \%$ compared with 2013, with regional differences (Table 1). Slight changes occurred when compared with 2015: WS decreased by $0.7 \%$, DSW dropped by $11.3 \%$, and RH decreased by $2.2 \%$. Overall, it can be seen that the annual haze days have a certain degree of correlations negatively with WS and positively with DSW. Detailed analysis linking $\mathrm{PM}_{2.5}$ and meteorology will be given in the Results and discussions section. 
Table 1. National and regional environmental meteorology in 2019 and comparisons with 2015 and 2013.

\begin{tabular}{|c|c|c|c|c|c|c|c|c|c|c|c|c|}
\hline \multirow[t]{2}{*}{ Region } & \multicolumn{3}{|c|}{ Wind speed } & \multicolumn{3}{|c|}{ Days with small wind } & \multicolumn{3}{|c|}{ Relative humidity } & \multicolumn{3}{|c|}{ Haze (days) } \\
\hline & $\begin{array}{r}\text { Avg } \\
\left(\mathrm{ms}^{-1}\right)\end{array}$ & $\begin{array}{r}\text { vs. } 2015 \\
(\%)\end{array}$ & $\begin{array}{r}\text { vs. } 2013 \\
(\%)\end{array}$ & Days & $\begin{array}{r}\text { vs. } 2015 \\
(\%)\end{array}$ & $\begin{array}{r}\text { vs. } 2013 \\
(\%)\end{array}$ & $\%$ & $\begin{array}{r}\text { vs. } 2015 \\
(\%)\end{array}$ & $\begin{array}{r}\text { vs. } 2013 \\
(\%)\end{array}$ & Days & vs. 2015 & vs. 2013 \\
\hline National & 2.2 & -0.7 & +4.5 & 129.8 & -11.3 & -15.1 & 60.1 & -2.2 & -3.9 & 25.7 & -19.0 & -21.2 \\
\hline BTH & 2.0 & -8.6 & -2.2 & 131.0 & +14.7 & +9.0 & 56.7 & -2.6 & -4.2 & 45.2 & -20.4 & -26.1 \\
\hline BTH+ & 2.0 & -9.9 & -1.0 & 114.4 & +11.4 & -5.6 & 58.3 & -3.9 & +0.6 & 54.5 & -34.8 & -30.3 \\
\hline YRD & 2.1 & +2.1 & -4.7 & 114.1 & -11.2 & +5.2 & 76.3 & -0.9 & +5.5 & 34.0 & -43.8 & -54.9 \\
\hline FWP & 1.9 & +0.3 & +10.9 & 122.8 & -12.1 & -25.2 & 59.9 & -2.9 & +3.3 & 51.6 & -44.2 & -43.8 \\
\hline PRD & 2.0 & +1.9 & -10.4 & 118.5 & +16.2 & +14.4 & 79.7 & -8.0 & +10.3 & 3.1 & -10.3 & -34.3 \\
\hline NEC & 2.7 & +3.6 & +12.9 & 55.8 & -33.7 & -38.4 & 61.6 & -2.8 & -5.8 & 13.6 & -30.8 & -12.4 \\
\hline CEN & 1.8 & +3.2 & +0.4 & 172.1 & -9.4 & -2.8 & 77.9 & -1.9 & +6.9 & 30.3 & -27.9 & -23.2 \\
\hline SWC & 1.7 & +3.7 & +12.2 & 180.7 & -13.3 & -16.3 & 74.7 & -0.9 & +5.7 & 11.1 & -12.1 & -12.4 \\
\hline NWC & 1.9 & -8.4 & +4.3 & 146.8 & -2.7 & -9.5 & 58.5 & 1.5 & +2.8 & 20.2 & -14.7 & -6.6 \\
\hline
\end{tabular}

Note: “+" increased; “-" decreased.

\subsection{EMI - the Environmental Meteorological Index}

Due to the complicated interactions of emissions, meteorology and atmospheric processes, a single set of meteorological factors or a combination of them cannot quantitatively attribute the individual factor to the changes in concentration observed.

In order to quantitatively assess the impacts of meteorological conditions on the changes in air pollution levels, an EMI is defined as follows. For a defined atmospheric column $(h)$ at a time $t$, an EMI is defined as an indication of atmospheric pollution level:

$\operatorname{EMI}(t)=\operatorname{EMI}(t 0)+\int_{t 0}^{t} \Delta \mathrm{EMI} \cdot \mathrm{d} t$,

where the $\triangle E M I$ is the tendency that causes the changes in pollution level in a time interval $\mathrm{d} t$ defined as

$\Delta \mathrm{EMI}=\mathrm{iEmid}+\mathrm{iTran}+\mathrm{iAccu}$,

where the iEmid is the difference between emission and deposition, and iTran and iAccu are the net (in minus out) advection transports and the vertical accumulation by turbulent diffusion in the column, respectively. A positive sign of each factor indicates a net flow of pollutants into the column, and vice versa.
Mathematically, these factors are expressed as

$$
\begin{aligned}
\text { iTran } & =\frac{1}{h C_{0}} \int_{0}^{h}\left(u \frac{\partial C}{\partial x}+v \frac{\partial C}{\partial y}+w \frac{\partial C}{\partial z}\right) \mathrm{d} z, \\
\text { iAccu } & =\frac{1}{h C_{0}} \int_{0}^{h}\left[\frac{\partial C}{\partial x}\left(K_{x} \frac{\partial C}{\partial x}\right)+\frac{\partial C}{\partial y}\left(K_{y} \frac{\partial C}{\partial y}\right)\right. \\
& \left.+\frac{\partial C}{\partial z}\left(K_{z} \frac{\partial C}{\partial z}\right)\right] \mathrm{d} z, \\
\text { iEmid } & =\frac{1}{h C_{0}} \int_{0}^{h}\left[\text { Emis }-\left(V_{\mathrm{d}}+L_{\mathrm{d}}\right)\right] \mathrm{d} z,
\end{aligned}
$$

where the tendency is normalized by a factor $C_{0}$. For an application of the EMI to the $\mathrm{PM}_{2.5}, C_{0}$ is set to equal $35 \mathrm{\mu g} \mathrm{m}^{-3}$, the national standard for $\mathrm{PM}_{2.5}$ in China (MEE, 2012), and the $\operatorname{EMI}(t)$ is written as $\operatorname{EMI}(t)_{2.5}$. If the $\mathrm{EMI}_{2.5}$ is less than 1 , the concentration level will reach or be better than the national standard.

It can be seen here that these key parameters account for the major meteorological factors which control the air pollutant levels, including wind speed and directions $(u, v, w)$, turbulent diffusion coefficients $\left(K_{x}, K_{y}, K_{z}\right)$ as well as dry and wet depositions $\left(V_{\mathrm{d}}\right.$ and $\left.L_{\mathrm{d}}\right)$. Therefore, under the conditions of unchanged emissions (Emis), the EMI variation reflects the impacts of meteorological factors on the levels of atmospheric pollutants. Furthermore, because of the inclusion of individual factors such as iTran, iAccu and iEmid, the variation of $\operatorname{EMI}(t)_{2.5}$ can be attributed to the variation of each factor, which gives more detailed information on the meteorological influence on the ambient pollutant concentration variations. It should be pointed out that the current EMI has only accounted explicitly for three major physical processes of iTran, iAccu, and iEmid that are closely related to the meteorological influences. However, the secondary for- 


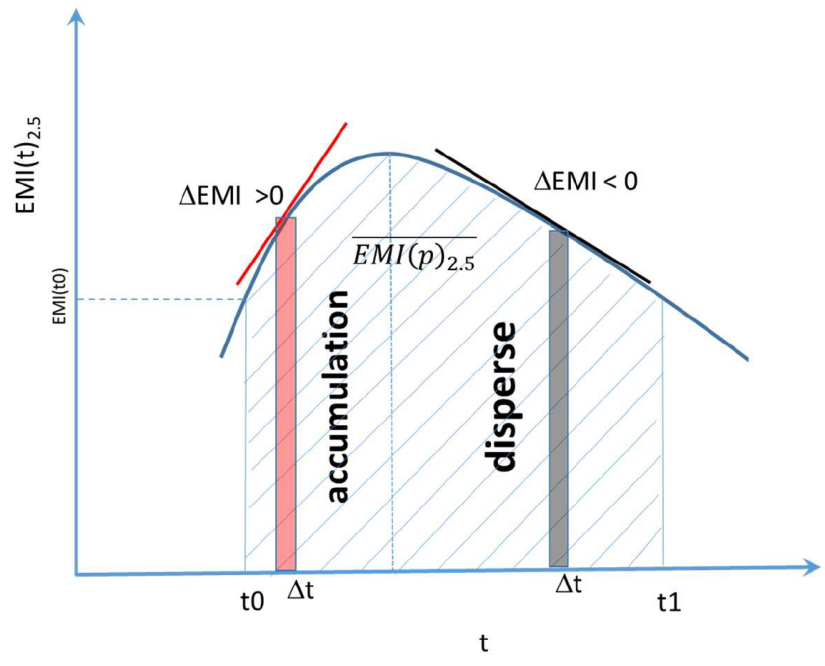

Figure 3. Relationship between the $\Delta \mathrm{EMI}, \operatorname{EMI}(t)_{2.5}$ and $\overline{\operatorname{EMI}(p)_{2.5}}$.

mation of aerosols is only implicitly considered in the EMI as the three major physical processes are calculated from the concentrations of aerosols $(C)$ as indicated in Eq. (3).

For a period of time $p$ ( $t 0$ to $t 1$ ) when the averaged pollutant level (e.g., $\mathrm{PM}_{2.5}$ ) is compared with $\operatorname{EMI}(t)_{2.5}$, the time integral has to be done to obtain the averaged index for the period, such as

${\overline{\operatorname{EMI}(p)_{2.5}}}_{t 1-t 0} \int_{t 0}^{t 1} \operatorname{EMI}(t)_{2.5} \mathrm{~d} t$.

The relationship among the $\Delta \operatorname{EMI}, \operatorname{EMI}(t)_{2.5}$ and $\overline{\operatorname{EMI}(p)_{2.5}}$ is illustrated in Fig. 3. It is clear that the $\operatorname{EMI}(t)_{2.5}$ is a function of time and can be used to reflect the pollution level

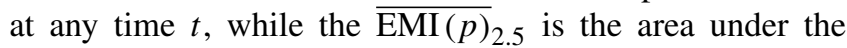
$\operatorname{EMI}(t)_{2.5}$ from times $t 0$ to $t 1$, which gives the averaged pollution levels for the period. The derivatives of $\operatorname{EMI}(t)_{2.5}$ are the $\triangle E M I$, which is a positive value when the pollution is being accumulated and a negative value when the pollution is being dispersed.

Therefore, for the period $p$ with $n$ discrete steps from $t 0$ to $t 1$, the $\overline{\operatorname{EMI}}(p)_{2.5}$ represents the averaged meteorological influences on $\mathrm{PM}_{2.5}$, while the sum of the positive $\triangle \mathrm{EMI}$ is the accumulation potentials and the sum of the negative $\triangle \mathrm{EMI}$ is the dispersing potentials as illustrated in Fig. 3. The relationship between them is derived as follows:

$$
\begin{aligned}
\overline{\operatorname{EMI}(p)}_{2.5} & =\frac{1}{n+1}[\operatorname{EMI}(0)+\operatorname{EMI}(1)+\operatorname{EMI}(2) \\
& +\cdots+\operatorname{EMI}(n)] \\
& =\frac{1}{n+1}[(n+1) \operatorname{EMI}(t 0)+n \Delta \operatorname{EMI}(1) \Delta t \\
& +(n-1) \Delta \operatorname{EMI}(2) \Delta t+(n-2) \Delta \operatorname{EMI}(3) \Delta t \\
& +(n-3) \Delta \operatorname{EMI}(4) \Delta t+\ldots+\Delta \operatorname{EMI}(n) \Delta t],
\end{aligned}
$$

where $n$ is the time steps in the period and the averaged EMI has been linked to the starting point $\operatorname{EMI}(0)$ and the changing rates of the $\operatorname{EMI}$, i.e., $\Delta \operatorname{EMI}(n)$, at each time step. For monthly simulations, the initial values $\operatorname{EMI}(t 0)$ for each month were set up by the averaged $\mathrm{PM}_{2.5}$ concentrations for the first day from 2013 to 2019 divided by the constant $C_{0}$ $\left(35 \mu \mathrm{g} \mathrm{m}^{-3}\right)$.

\subsection{Assessment framework of emission controls}

The $\mathrm{EMI}_{2.5}$ index provides a way to assess the meteorological impacts on the changes in $\mathrm{PM}_{2.5}$ concentrations at two time periods, i.e., January $2013(p 0)$ and January $2016(p 1)$, under the assumption of unchanged emissions. However, due to the national efforts of improving air quality, the year-byyear emissions are changing rapidly and unevenly across the country. The changes in both emissions and meteorology are tangled together to yield the observed changes in ambient concentrations. For policy makers, the emission reduction quantification is critical to guide further air quality improvements. The framework proposed here is to combine changes in the observed concentration levels and meteorology factors $\overline{\operatorname{EMI}(p)_{2.5}}$ to quantify the changes caused by emission changes only at two time periods.

The observed concentrations at $p 0$ and $p 1$ are defined as PM $(m 0, e 0)$ and PM $(m 1, e 1)$, where $(m 0, e 0)$ and $(m 1, e 1)$ indicate the meteorology and emission status at $p 0$ and $p 1$, respectively. The contribution to the observed concentration changes between $p 0$ and $p 1$ by sole emission changes or control measures is defined as

$\Delta \mathrm{EMIS}=\frac{\operatorname{PM}(m 0, e 1)-\mathrm{PM}(m 0, e 0)}{\operatorname{PM}(m 0, e 0)} \times 100 \%$,

where PM $(m 0, e 1)$ is a hypothetically non-measurable quantity, indicating the PM concentration at $p 1$ with emission $e 1$ and meteorology $m 0$, which does not exist in reality. An assumption is to be made to compute this quantity using the EMIs. It is assumed that

$\operatorname{EMI}(p 0)_{2.5} / \operatorname{EMI}(p 1)_{2.5}=\operatorname{PM}(m 0, e 1) / \operatorname{PM}(m 1, e 1)$,

which means that under the same emissions, the ratio of averaged EMIs under two meteorologies $(m 0, m 1)$ equals the 
ratio of PM concentrations under the same two meteorologies $(m 0, m 1)$. Given the nonlinear contributions of meteorology and emissions to the ambient PM concentrations or simulated EMIs, this assumption is a first-order approximation for the contributions of meteorology and emissions to the observed concentrations. Substituting PM $(m 0, e 1)$ calculated from Eqs. (7) to (6) will facilitate the estimate of percentage contribution of emission controls to the air quality improvement at two periods of time, independent of meteorology variations.

\subsection{Quantitative estimate of the EMI}

Finally, a process-based method is developed to calculate the EMI and its components, i.e., iEmid, iTran and iAccu. The main modeling framework used is the chemical weather modeling system MM5/CUACE, which is a fully coupled atmospheric model used at the CMA for national haze and air quality forecasts (Gong and Zhang, 2008; Zhou et al., 2012). CUACE is a unified atmospheric chemistry environment with four major functional sub-systems: emissions, gasphase chemistry, aerosol microphysics and data assimilation (Niu et al., 2008). Seven aerosol components, i.e., sea salts, sand/dust, EC, OC, sulfates, nitrates and ammonium salts, are sectioned into 12 size bins with detailed microphysics of hygroscopic growth, nucleation, coagulation, condensation, dry depositions and wet scavenging in the aerosol module (Gong et al., 2003). The gas chemistry module is based on the second generation of a Regional Acid Deposition Model (RADM II) mechanism with 63 gaseous species through 21 photo-chemical reactions and 121 gas-phase reactions applicable under a wide variety of environmental conditions especially for smog (Stockwell et al., 1990) and prepares the sulfate and SOA production rates for the aerosol module and for the aerosol equilibrium module ISORROPIA (Nenes et al., 1998) to calculate the nitrate and ammonium aerosols. This is the default method to treat the secondary aerosol formations in CUACE. For the EMI application of CUACE, another option was also adapted to compute the secondary aerosol formations by a highly parameterized method (Zhao et al., 2017) that computes the aerosol formation rates directly from the precursor emission rates of $\mathrm{SO}_{2}, \mathrm{NO}_{2}$ and VOC. This option was added to facilitate timely operational forecast requirements for the CMA. Both primary and precursor emissions of PM are based on the 2016 MEIC Inventory (http://www.meicmodel.org/, last access: 31 December 2020) developed by Tsinghua University for China.

In order to quantitatively obtain each term defined in Eq. (3), the CUACE model was modified to extract the change rates for the processes involved. Driven by the reanalysis meteorological data, the new system CUACE/EMI can be used to calculate each term in $\triangle \mathrm{EMI}$ at each time step $(\Delta t)$.

In summary, this section presents a systematic platform to separate and assess the impacts of the meteorology and emis-

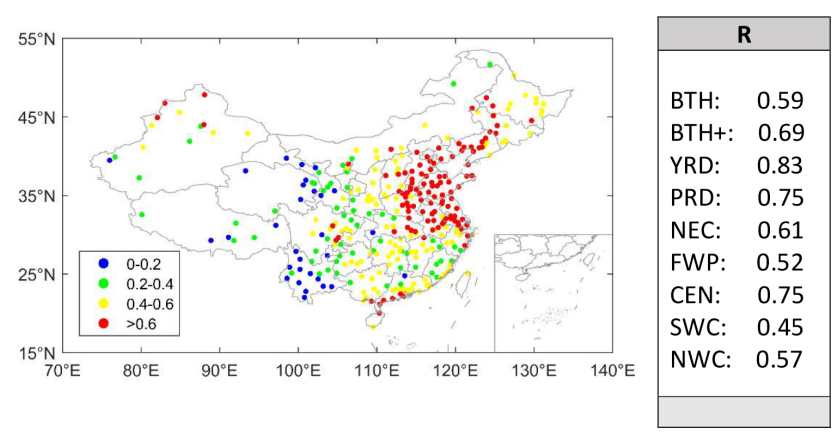

Figure 4. Correlation coefficients $(R)$ between the $\mathrm{EMI}_{2.5}$ and the observed $\mathrm{PM}_{2.5}$ daily concentrations across China for 2017 and for typical regions averaged between 2013 and 2019.

sions on the ambient concentration changes. The $\overline{\operatorname{EMI}(p)}_{2.5}$ and $\Delta$ EMIS form the basis for the assessment. In the Results and discussions section, the application of the platform is presented to assess the fine particular matter $\left(\mathrm{PM}_{2.5}\right)$ changes in China.

\section{Results and discussions}

\subsection{Validation of the EMI by observations}

Under the conditions of no changes in annual emissions for $\mathrm{PM}_{2.5}$ and its precursors, the daily $\mathrm{EMI}_{2.5}$ was computed by CUACE from 2013 to 2019 on a $15 \times 15 \mathrm{~km}$ resolution across China and accompanied by its contribution components: iTran, iAccu and iEmid. However, in order to reflect the significant changes in industrial and domestic energy consumptions within a year in China, a monthly emission (Wang et al., 2011) variation was applied to the emission inventory for computing the $\mathrm{EMI}_{2.5}$, which more realistically reflects the meteorology contributions to the $\mathrm{PM}_{2.5}$ concentrations.

To evaluate the applicability of $\mathrm{EMI}_{2.5}$, the index was compared with the observed $\mathrm{PM}_{2.5}$ concentrations. Figure 4 shows the spatial distribution of correlation coefficients between $\mathrm{PM}_{2.5}$ and $\mathrm{EMI}_{2.5}$ for 2017 for all of China. The correlation coefficients between $\mathrm{EMI}_{2.5}$ and $\mathrm{PM}_{2.5}$ concentrations are greater than 0.4 for most of eastern China and greater than 0.6 for most of the assessment regions. Less satisfactory correlation was found in western China, possibly due to complex terrain and less accurate emission data over there. Furthermore, due to the uncertainty in emissions and the difference in model performance for year-to-year meteorology simulations, the correlation coefficients may differ for different years. Overall, the good correlation between them merits the application of $\mathrm{EMI}_{2.5}$ to quantify the meteorology impact on $\mathrm{PM}_{2.5}$.

To further illustrate the applicability of $\mathrm{EMI}_{2.5}$, the difference of various conditions between December 2014 and December 2015 in the BTH region was also analyzed when 
(a) Dec. $\mathrm{EMI}_{25}$

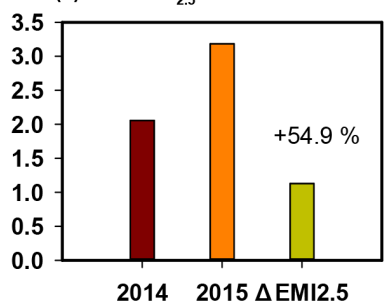

(c) $\Delta \mathrm{EMI}_{2.5}$ Controbutions

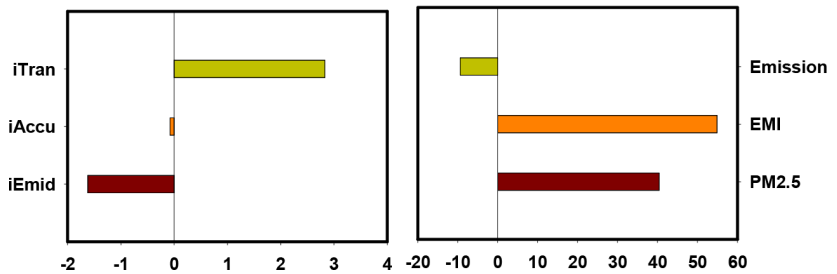

Figure 5. (a) The monthly averaged $\mathrm{EMI}_{2.5}$ and (b) monthly $\mathrm{PM}_{2.5}$ for the Decembers of 2014 and 2015 over BTH. (c) Contributions of the sub-index to the $\mathrm{EMI}_{2.5}$ change and (d) contributions of emission and meteorology changes to $\mathrm{PM}_{2.5}$ change for the Decembers from 2014 to 2015 , respectively.

a significant change in air quality and meteorological conditions occurred. The winter of 2015 was accompanied by a strong El Niño (ENSO) event, resulting in significant anomalies for meteorological conditions in China. Analysis shows that the meteorological conditions in December 2015 (compared to December 2014) had several important anomalies, including that the surface southeasterly winds were significantly enhanced in the North China Plain (NCP) and the wind speeds were decreased in the middle north of eastern China and slightly increased in the south of eastern China. A study suggests that the 2015 El Niño event had significant effects on air pollution in eastern China, especially in the NCP region, including the capital city of Beijing, in which aerosol pollution was significantly enhanced in the already heavily polluted capital city of China (Chang et al., 2016).

Figure 5 shows the monthly average $\mathrm{EMI}_{2.5}, \mathrm{PM}_{2.5}$ and contribution of the sub-index to total $\mathrm{EMI}_{2.5}$ in December 2014 and 2015 over the BTH region. The monthly average $\mathrm{EMI}_{2.5}$ increases by about $54.9 \%$ from 2.1 in December 2014 to 3.2 in December 2015, indicating worsening meteorological conditions for $\mathrm{PM}_{2.5}$ pollution. The increase in $\mathrm{EMI}_{2.5}$ is mainly contributed by adverse atmospheric transport conditions (Fig. 5c), which results in the increase in $\mathrm{EMI}_{2.5}$ reaching 3.2. With the increase in background concentration, the deposition and vertical diffusion also increase and offset the impact of adverse transport conditions to some extent.

The worsening meteorological conditions represented by $\mathrm{EMI}_{2.5}$ were also supported by the observations for the two periods. The observed day with DSW, wind speed less than $2 \mathrm{~m} \mathrm{~s}^{-1}$ ) reveals that, except for part of southern Hebei Province, the DSW increases by $5-15 \mathrm{~d}$ for 2015 in most meteorological stations in the BTH region (Fig. 6a), which indicates a large decrease in local diffusion capability. The comparison of the wind rose map shows that the decrease in northwesterly wind and the increase in southwesterly and northeasterly wind occurred in December 2015 (Fig. 6b). The change in wind fields indicates more pollutants were transported to the BTH region from Shandong, Jiangsu, Henan, and Northeast China. These variations indirectly validate the conclusions of adverse atmospheric transport conditions with high iTran in December 2015.

Based on the assessment method of emission contribution to the observed trend (Eqs. 6 and 7), the emission reduction in December 2015 as compared to 2014 was estimated to contribute about $9.4 \%$ (Fig. $5 \mathrm{~d}$ ) to the $\mathrm{PM}_{2.5}$ concentration decrease, compensating for the large increase caused by meteorology, which is comparable with previous studies of about $8.6 \%$ reduction in emissions (Liu et al., 2017; He et al., 2017a) for the same 2 months. In other words, without the regional emission reduction efforts, the observed $\mathrm{PM}_{2.5}$ concentration in December 2015 would have had a similar rate of $54.9 \%$ increase to the worsening meteorology conditions as compared with December 2014. This assessment of emission reduction is supported by the estimate of emission inventories for the BTH region in the Decembers of 2014 and 2015 by Zheng et al. (2019), who found out that the monthly emission strengths for $\mathrm{PM}_{2.5}, \mathrm{SO}_{2}, \mathrm{NO}_{x}, \mathrm{VOCs}$ and $\mathrm{NH}_{3}$ in 2015 were reduced by $22.0 \%, 6.9 \%, 2.5 \%, 2.5 \%$ and $2.5 \%$, respectively, as compared with 2014 . The sensitivity and the nonlinear response of $\mathrm{PM}_{2.5}$ concentrations to the air pollutant emission reduction in the BTH region (Zhao et al., 2017) have been estimated to be about 0.43 for both primary inorganic and organic $\mathrm{PM}_{2.5}, 0.05$ for $\mathrm{SO}_{2},-0.07$ for $\mathrm{NO}_{x}$, 0.15 for VOCs, and 0.1 for $\mathrm{NH}_{3}$. Combining the emission reduction percentages between the Decembers of 2014 and 2015 and the nonlinear response of emissions to the $\mathrm{PM}_{2.5}$ concentrations results in an approximately $10.2 \%$ ambient $\mathrm{PM}_{2.5}$ concentration reduction due to the emission changes. This is very close to the estimate of emission reduction contribution to the December $\mathrm{PM}_{2.5}$ concentration difference of about $9.4 \%$ between 2014 and 2015 by the EMI framework.

The applicability of the EMI to assess the meteorology and emission changes is also evaluated by results from a full chemical transport model (MM5/CUACE) and observational data for $\mathrm{PM}_{2.5}$ in China for the Novembers of 2017 and 2018. The averaged $\mathrm{EMI}_{2.5}$ and observational data for the 2 months were used to estimate the emission change ratio (ERatio in Table 2) by Eqs. (6)-(7) from 2017 to 2018. In order to evaluate the correctness of this emission change estimate, the E-Ratio was used to adjust the emissions for November 2018 from the base emissions of the same month for 2017, which were then implemented in the MM5/CUACE to simulate the $\mathrm{PM}_{2.5}$ concentrations for the 2 months, respectively. If the simulated concentration differences (M-Ratio) for the 2 months were comparable with the observed concentration differences (O-Ratio), it can be concluded that the 
(a)

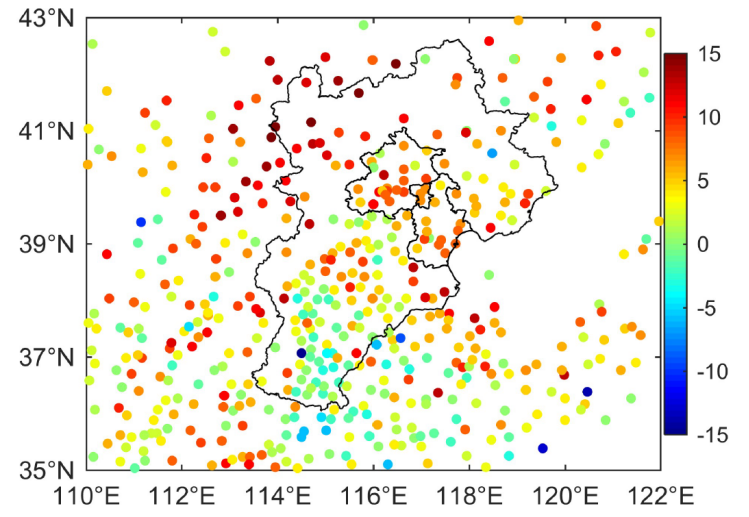

(b)

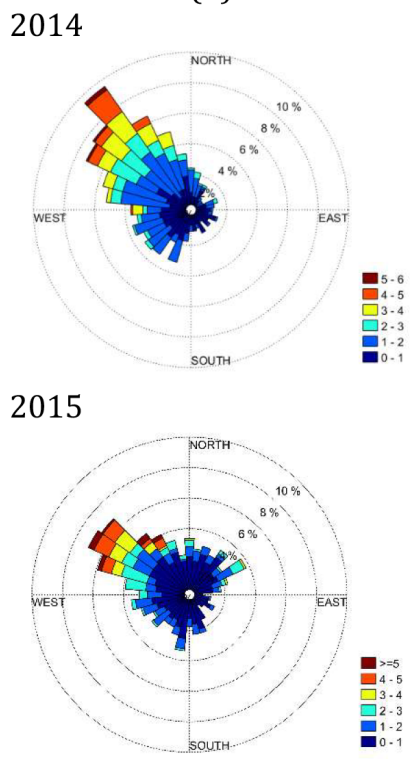

Figure 6. (a) The change in DSW (days) from December 2014 to December 2015 (December 2015-December 2014) and (b) wind rose maps in December 2014 and December 2015 over the BTH region.

Table 2. Comparison of $\mathrm{PM}_{2.5}$ concentrations in the Novembers of 2017 and 2018 from ambient observations and from CTM simulations by EMI-derived estimated emission changes. The emission ratio is indicated by bold font and the two concentration ratios are in bold italic font.

\begin{tabular}{lrr|rrr|r|rr|rr}
\hline City & \multicolumn{2}{c}{ EMI $_{2.5}$} & \multicolumn{3}{c|}{ Observations } & Emission changed & \multicolumn{3}{c}{ CTM simulated } \\
\cline { 2 - 9 } & 2017 & 2018 & 2017 & 2018 & O-Ratio & E-Ratio & 2017 & 2018 & M-Ratio \\
\hline Beijing & 1.8 & 3.6 & 45.7 & 72.8 & $\mathbf{1 . 5 9}$ & $\mathbf{0 . 8 0}$ & 42.3 & 67.5 & $\mathbf{1 . 5 9}$ \\
Shanghai & 2.7 & 2.6 & 42.0 & 40.1 & $\mathbf{0 . 9 5}$ & $\mathbf{1 . 0 0}$ & 52.7 & 51.2 & $\mathbf{0 . 9 7}$ \\
Jinan & 3.3 & 4.9 & 57.1 & 85.8 & $\mathbf{1 . 5 0}$ & $\mathbf{1 . 0 2}$ & 62.4 & 90.9 & $\mathbf{1 . 4 6}$ \\
Xian & 2.4 & 2.7 & 94.8 & 84.7 & $\mathbf{0 . 8 9}$ & $\mathbf{0 . 7 9}$ & 95.1 & 86.9 & $\mathbf{0 . 9 1}$ \\
Zhengzhou & 4.3 & 6.2 & 73.9 & 100.4 & $\mathbf{1 . 3 6}$ & $\mathbf{0 . 9 6}$ & 80.4 & 91.1 & $\mathbf{1 . 1 3}$ \\
Shenyang & 1.8 & 2.7 & 40.2 & 48.9 & $\mathbf{1 . 2 1}$ & $\mathbf{0 . 8 2}$ & 73.3 & 120.1 & $\mathbf{1 . 6 3}$ \\
\hline
\end{tabular}

emission change estimated by the EMI framework was reliable and could approximately represent the actual emission changes. Table 2 summarizes the analysis results of this evaluation for six typical cities. It is clear that the O-Ratios for the six cities are very comparable with M-Ratios, indicating that the EMI framework can be reasonably used to estimate the emission changes over time.

\section{2 $\quad \mathrm{PM}_{2.5}$ trends and meteorological contributions}

The annual averaged $\mathrm{PM}_{2.5}$ concentrations in China have been decreased significantly from 2013 to 2019. Figure 7 shows the observed spatial distribution of national $\mathrm{PM}_{2.5}$ concentrations from 2013 to 2019, respectively. These spatial distributions are consistent with those of primary and precursor emissions of $\mathrm{PM}_{2.5}$ (Wang et al., 2011), pointing out the fundamental cause of the air pollution in China. From the spatial distributions, it is clear that the regions of BTH,
FWP, CEN and NWC had the highest $\mathrm{PM}_{2.5}$ concentrations among the nine regions. Even though the national concentrations have been reduced significantly from 2013 by reducing emissions, the pollution center of particular matters has not been changed very much, located in southern Hebei Province and indicating the macroeconomic structure has not gone through a great change yet. Another phenomenon that can be seen from the distribution is that in Northwest China, especially in some cities of Xinjiang and Ningxia provinces, the $\mathrm{PM}_{2.5}$ concentrations were on an increasing trend, due to certain migrating industries from developed regions in East China.

Averaged for the nation, nine focused regions and Beijing, the $\mathrm{PM}_{2.5}$ trend lines were shown in Fig. 2. It is seen that all regions have had a large reduction of more than $35 \%$ in surface $\mathrm{PM}_{2.5}$ concentrations in 2019 as compared with those in 2013. The averaged national annual concentration 


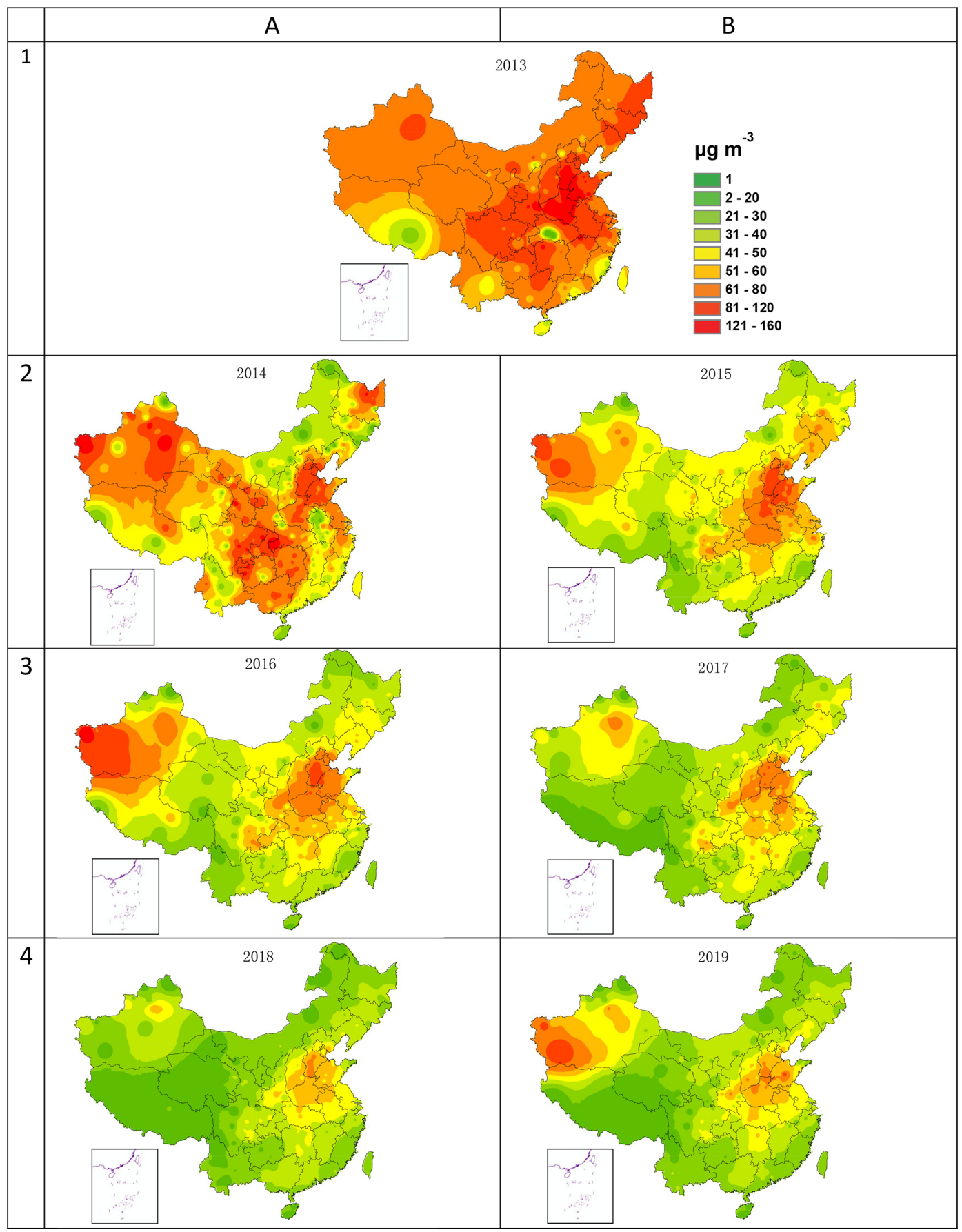

Figure 7. Regional annual $\mathrm{PM}_{2.5}$ concentration distributions from 2013 to 2019.

at $36 \mu \mathrm{g} \mathrm{m}^{-3}$ has been very close to the national standard of $35 \mathrm{\mu g} \mathrm{m}^{-3}$, while the concentrations in the PRD, SWC and NEC regions have been below the standard. Regions above the standard are BTH+, BTH, YRD, CEN and FWP. Regionally, the largest drop percentage of $\mathrm{PM}_{2.5}$ was seen in the NEC and NWC regions (Fig. 8), reaching over $50 \%$ compared with 2013. In the BTH, BTH+, FWP and CEN regions, the reduction was in the range of $45 \%$ to $50 \%$, while in YRD and PRD the reduction was around $35 \%$.

As one of the key factors in controlling the ambient $\mathrm{PM}_{2.5}$ concentration variations, the annual meteorological fluctuations, i.e., $\mathrm{EMI}_{2.5}$, from 2014 to 2019 with 2013 as the base year, are shown in Fig. 9 for nine regions. Generally, the annual $\mathrm{EMI}_{2.5}$ shows a positive or negative variation, reflecting the meteorological features for that specific region. Except 


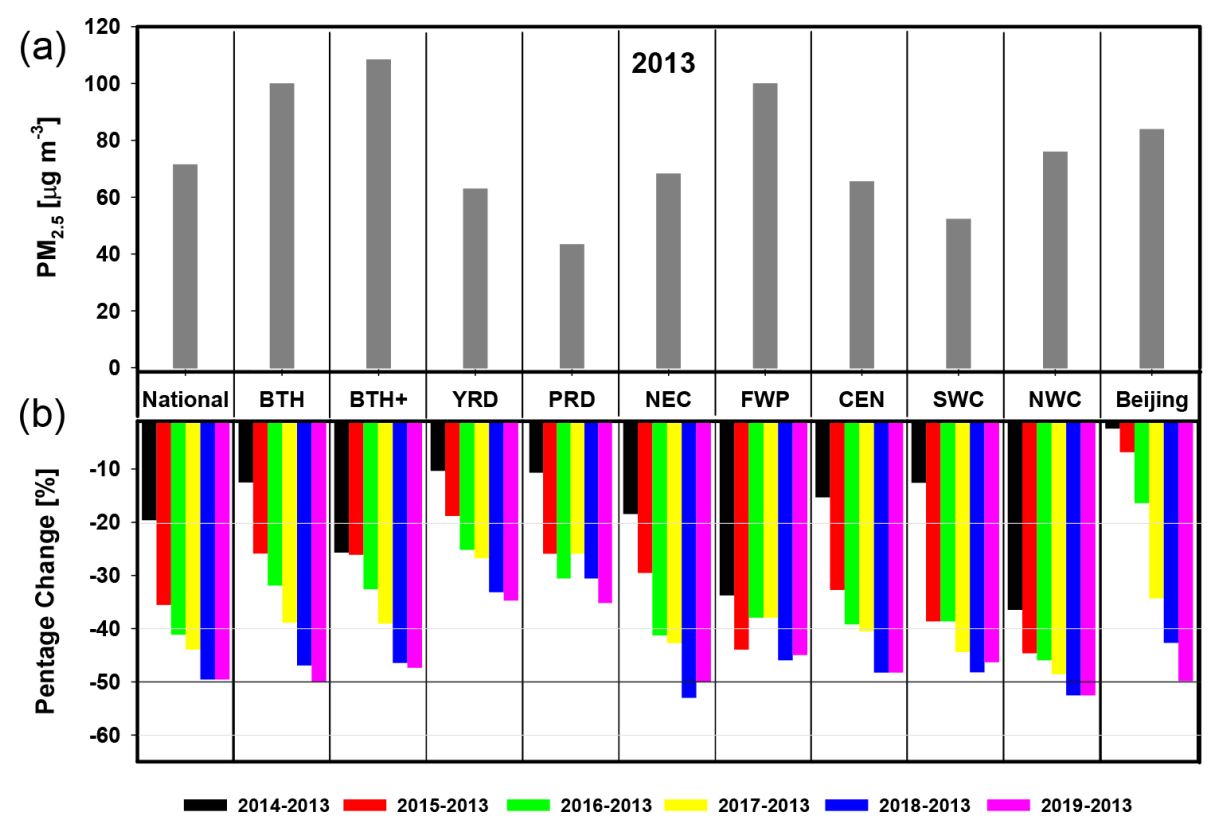

Figure 8. Annual averaged $\mathrm{PM}_{2.5}$ concentrations in 2013 (a) and corresponding changing rates (b) from 2014 to 2019 as compared with 2013 for the nation, nine regions and Beijing.

for a couple of regions or years, most of the fluctuations are within $5 \%$ as compared with 2013 and have no definite trend. It can be inferred that the meteorological conditions are possibly responsible for about $5 \%$ of the annual $\mathrm{PM}_{2.5}$ averaged concentration fluctuations from 2013 to 2019 (Fig. 9b). This is consistent with what has been assessed in Europe by Andersson et al. (2007).

The variations in meteorological contributions $\left(\mathrm{EMI}_{2.5}\right)$ to $\mathrm{PM}_{2.5}$ for the heavy pollution seasons of fall and winter (1 October to 31 March) generally follow the same fluctuating pattern as the annual average but are much larger than the average (Fig. 9c), over $5 \%$ for most of the regions and years. For specific regions and years, e.g., BTH, YRD, NEC, SWC and CEN, the variations are between $10 \%$ and $20 \%$ as compared with 2013. Since the $\mathrm{PM}_{2.5}$ concentrations are much higher in the pollution season, the larger meteorology variations in fall-winter would exercise more controls on the heavy pollution episodes than the annual averaged concentrations, signifying the importance of meteorology in regulating the winter pollution situations.

It is found that though most of the regions have a fluctuating $\mathrm{EMI}_{2.5}$ in the pollution season during the 2014-2019 period (Fig. 9c), the YRD and FWP show consistent favorite and unfavorite meteorological conditions, respectively. BTH has witnessed the same unfavorite conditions as FWP, except in 2017. In other words, in BTH and FWP, the decrease in ambient concentrations of $\mathrm{PM}_{2.5}$ from 2014 to 2019 has to overcome the difficulty of worsening meteorological conditions with larger control efforts.

\subsection{Attribution of control measures to the $\mathbf{P M}_{2.5}$ trend}

As it is well known that the final ambient concentrations of any pollutants result from the emission, meteorology and atmospheric physical and chemical processes, separating emissions and meteorology contributions to the pollution-level reduction entails a combined analysis of them. The analysis in Sect. 3.2 shows that from 2013 to 2019 , the national averaged $\mathrm{PM}_{2.5}$ as well as those for nine separate regions were all showing a gradual decline trend (Fig. 8). By 2019, $45 \%-$ $50 \%$ of reductions in surface $\mathrm{PM}_{2.5}$ concentrations were achieved, while the meteorology contributions did not show a definite trend as from 2013, clearly pointing out the contribution of emission reductions in the trend. Using the analysis framework for separating emissions from meteorology based on the monitoring data of $\mathrm{PM}_{2.5}$ and $\mathrm{EMI}_{2.5}$ (Sect. 2.4), the emission change contributions are estimated.

Figure 10 shows the 2013 base emissions of $\mathrm{PM}_{2.5}$ (Zhao et al., 2017) and the annual changes in the emission contributions to the $\mathrm{PM}_{2.5}$ concentrations from 2014 to 2019 as estimated from the $\mathrm{EMI}_{2.5}$ and observed $\mathrm{PM}_{2.5}$. For the emissions, it is found that the unit area emissions match better with ambient concentrations of $\mathrm{PM}_{2.5}$ in regions than the total emissions and the high-emission regions are BTH, BTH+, YRD, PRD and FWP in 2013. Nationally by 2019, the emission reduction contributions to the ambient $\mathrm{PM}_{2.5}$ trend ranged from $32 \%$ to $52 \%$ of the total $\mathrm{PM}_{2.5}$ decrease percentage, while in the $\mathrm{BTH}$ and $\mathrm{BTH}+$ regions the reduction was more than $49 \%$ from the 2013 base year emissions, leading the national emission reduction campaign. The emission reduction rates clearly illustrate the effectiveness 

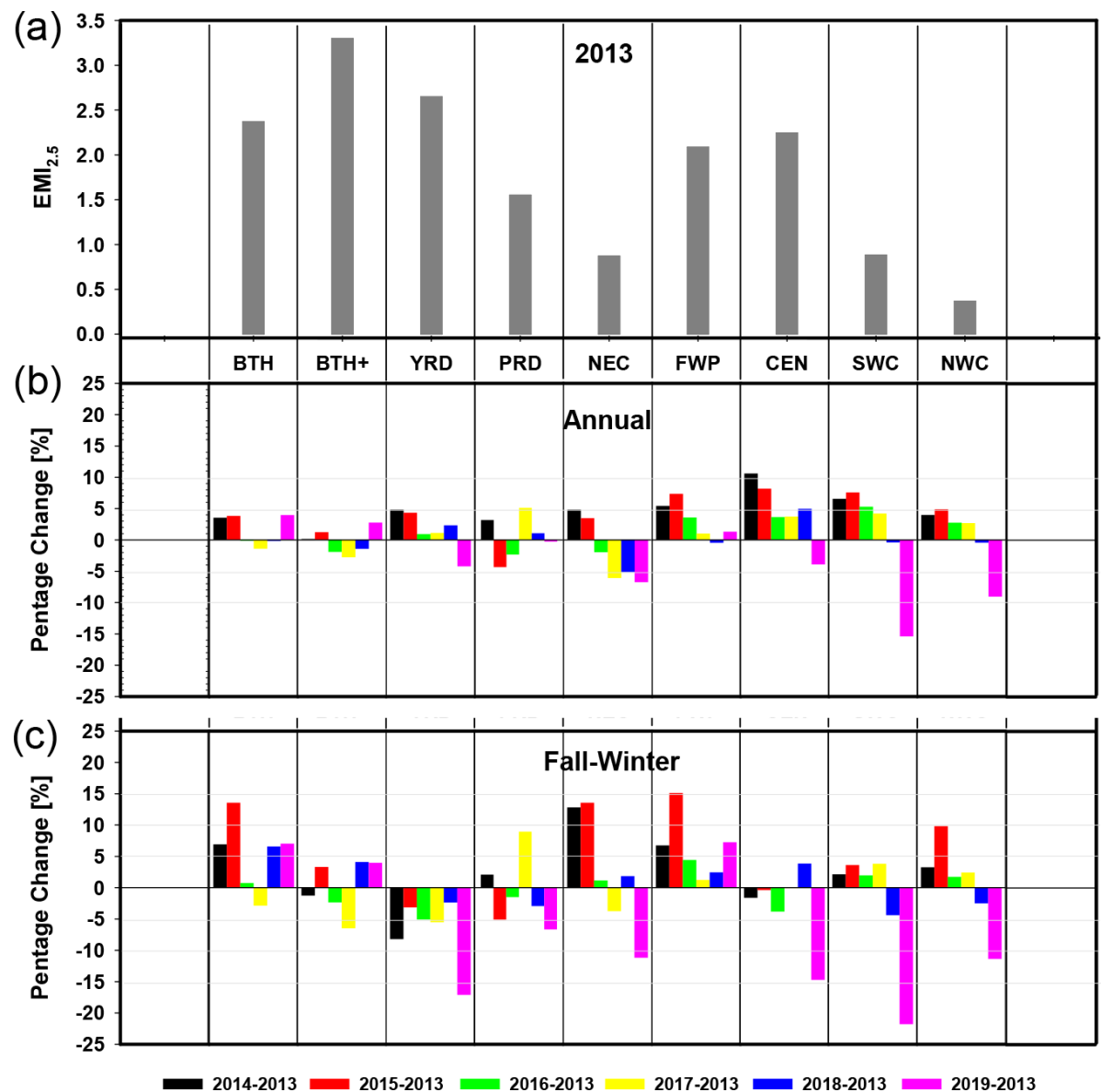

Figure 9. Annual averaged $\mathrm{EMI}_{2.5}$ in 2013 (a) and corresponding changing rates for the annual average (b) and for the fall-winter seasons (c) from 2014 to 2019 as compared with 2013 in nine regions.

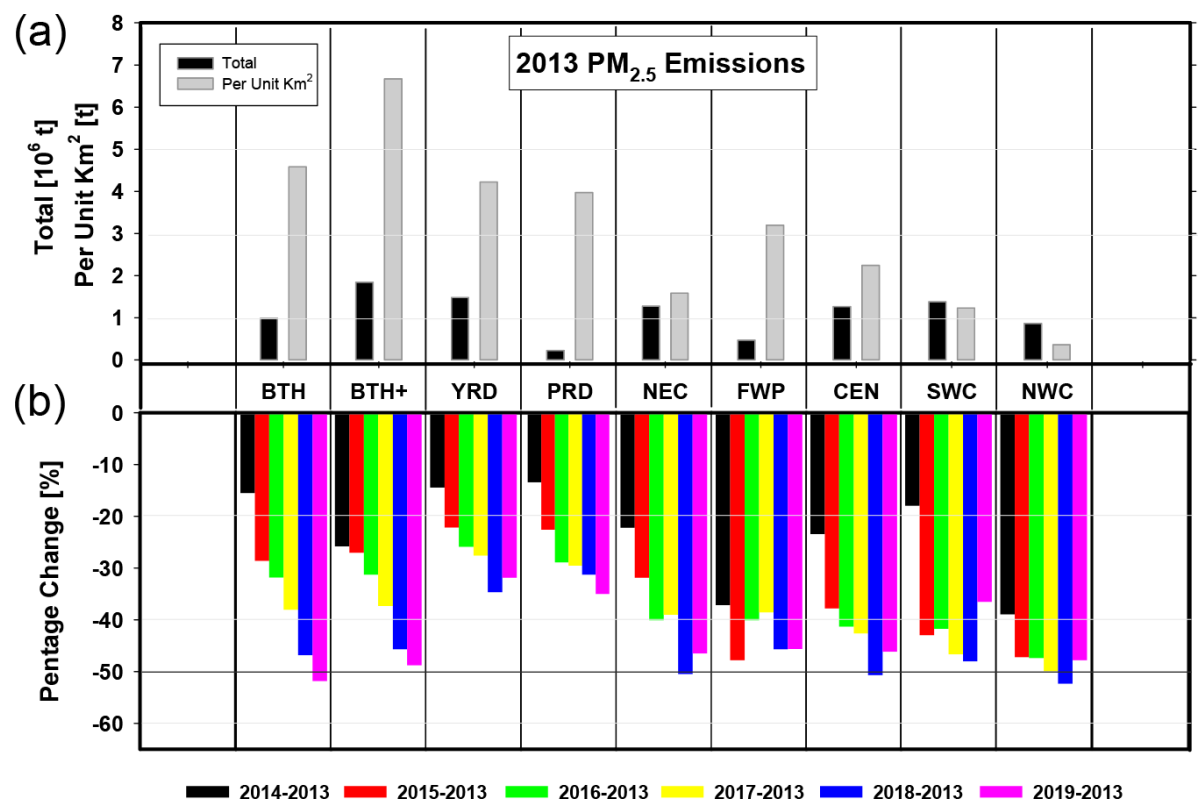

Figure 10. Annual $\mathrm{PM}_{2.5}$ emissions (total and per unit $\mathrm{km}^{2}$ ) for 2013 (a) and corresponding changing rates (b) from 2014 to 2019 as compared with 2013 in nine regions. 
Table 3. Observed $\mathrm{PM}_{2.5}$ difference between 2019 and 2015 as well as its attributions to meteorology and control measures for all of China, Beijing and nine regions.

\begin{tabular}{|c|c|c|c|c|c|c|}
\hline \multirow[t]{3}{*}{ Regions } & \multirow{2}{*}{\multicolumn{2}{|c|}{ Observed $\mathrm{PM}_{2.5}$ difference }} & \multicolumn{4}{|c|}{ Attributions } \\
\hline & & & \multicolumn{2}{|c|}{ Meteorology (EMI) } & \multicolumn{2}{|c|}{ Emission controls } \\
\hline & $\left(\mu \mathrm{g} \mathrm{m}^{-3}\right)$ & $(\%)$ & $\left(\mu \mathrm{g} \mathrm{m}^{-3}\right)$ & Relative \% & $\left(\mu \mathrm{g} \mathrm{m}^{-3}\right)$ & Relative $\%$ \\
\hline National & -10 & -21.7 & -4.1 & -40.9 & -5.9 & -59.1 \\
\hline ВTH & -24 & -32.4 & +0.1 & +0.4 & -24.1 & -100.4 \\
\hline BTH+ & -23 & -28.8 & +1.2 & +5.4 & -24.2 & -105.4 \\
\hline YRD & -10 & -19.6 & -4.0 & -39.7 & -6.0 & -60.3 \\
\hline PRD & -4 & -12.5 & +1.4 & +36.0 & -5.4 & -136.0 \\
\hline NEC & -14 & -29.2 & -4.4 & -31.6 & -9.6 & -68.4 \\
\hline FWP & -1 & -1.8 & -3.6 & -362.2 & +2.6 & +262.2 \\
\hline CEN & -12 & -23.1 & -5.5 & -45.5 & -6.5 & -54.5 \\
\hline SWC & -4 & -12.5 & -8.5 & -211.5 & +4.5 & +111.5 \\
\hline NWC & -6 & -14.3 & -5.5 & -92.1 & -0.5 & -7.9 \\
\hline Beijing & -36 & -46.2 & +3.4 & +9.4 & -39.4 & -109.4 \\
\hline
\end{tabular}

Note: “+” increased; “-” decreased.

of the nationwide emission control strategies implemented since 2013, and the emission reduction is the dominant factor for the ambient $\mathrm{PM}_{2.5}$ declining trend in China. Taking the analysis data of $\mathrm{PM}_{2.5}$ and $\mathrm{EMI}_{2.5}$ from this study for the $\mathrm{BTH}+$ region from 2013 to 2017 , it is found that the control strategy contributed more than $90 \%$ to the $\mathrm{PM}_{2.5}$ decline. Chen et al. (2019) estimated that the control of anthropogenic emissions contributed $80 \%$ of the decrease in $\mathrm{PM}_{2.5}$ concentrations in Beijing from 2013 to 2017.

Regionally, the emission reduction trends from 2014 to 2019 display some unique characteristics. For the regions of BTH, BTH+ and PRD, the year-by-year reduction rate is consistent, indicating that regardless of fluctuations in meteorology, these regions have had an effective emission control strategy and maintained the emission reduced year by year since 2014. However, in some regions such as FWP, NEC, SWC and NWC, the emission reduction rates were fluctuating from 2014 to 2019, implying that the emissions in these regions were increased in certain years. Especially in FWP from 2016 to 2017, the emissions were estimated to be increased by about $10 \%$ and then decreased in 2018 and 2019, despite the fact that FWP experienced unfavorite meteorological conditions during this period.

The year of 2015 is a special year in the history of China air pollution control. Though the systematical and network observations of $\mathrm{PM}_{2.5}$ started in China from 2013, it took about 2 years (until 2015) to evolve to the current status in terms of spatial coverage and observational station numbers, establishing a consistent and statistically comparable national network. In the same year, the Environmental Protection Law of the People's Republic of China took effect in January, signalizing the stage of lawful control of air pollution. From the regulation assessment point of view, the im- pact by emission changes from 2015 was relevant to the interests of management to show how effective the law was.

Table 3 summarizes the $\mathrm{PM}_{2.5}$ difference between 2019 and 2015 and the relative contributions of meteorology and emission changes to the difference for all of China, Beijing and nine regions. Once again, as of the end of 2019, the $\mathrm{PM}_{2.5}$ concentrations are all reduced from 2015, ranging from $-1.8 \%$ in FWP to $-46.2 \%$ in Beijing. During this period of time, regions of $\mathrm{BTH}, \mathrm{BTH}+, \mathrm{PRD}$ and Beijing had encountered unfavorite meteorological conditions with positive $\mathrm{EMI}_{2.5}$ changes, which indicated that for these regions, emission reductions were not only to maintain the decline trend, but also to offset the unfavorite meteorological conditions in order to achieve the observed reductions in ambient $\mathrm{PM}_{2.5}$ concentrations. By contrast, for the regions of FWP and SWC, the emission control impacts were to deteriorate the concentrations, implying an increase in emissions to restrain the $\mathrm{PM}_{2.5}$ concentration decrease by favorite meteorological conditions. For other regions, both meteorology and emission controls contributed to $\mathrm{PM}_{2.5}$ decrease from 2015 to 2019 , with the control measures contributing $-7.9 \%$ in NWC to $-68.4 \%$ in NEC (Table 3 ).

Therefore, due to the diversity of meteorological conditions and emission distributions in China, their impacts on ambient $\mathrm{PM}_{2.5}$ concentrations display unique regional characteristics. Overall, the emission controls are the dominant factor in contributing the declining trend in China from 2013 to 2019. However, in certain regions or certain periods of years, emissions were found to be increased even with favorite meteorological conditions, which means the design of national control strategies has to take both meteorology and emission impacts simultaneously in order to achieve maximum results. 


\section{Conclusions}

Based on a 3-D chemical transport model and its process analysis, an Environmental Meteorological Index (EMI 2.5$)$ and an assessment framework have been developed and applied to the analysis of the $\mathrm{PM}_{2.5}$ trend in China from 2013 to 2019. Compared with observations, the $\mathrm{EMI}_{2.5}$ can realistically reflect the contribution of meteorological factors to the $\mathrm{PM}_{2.5}$ variations in the time series with impact mechanisms and can be used as an index to judge whether the meteorological conditions are favored or not for the $\mathrm{PM}_{2.5}$ pollutions in a region or time period. In conjunction with the observational trend data, the $\mathrm{EMI}_{2.5}$-based framework has been used to quantitatively assess the separate contribution of meteorology and emission changes to the time series for nine regions in China. Results show that for the period of 2013 to 2019, the $\mathrm{PM}_{2.5}$ concentrations dropped continuously throughout China, by about $50 \%$ on the national average. In the regions of NWC, NEC, BTH, BEIJING, CEN, $\mathrm{BTH}+$, and SWC, the reduction was in the range of $46 \%$ to $53 \%$, while in FWP, PRD, and YRD, the reduction was from $45 \%$ to $35 \%$. It is found that the control measures of emission reduction are the dominant factors in the $\mathrm{PM}_{2.5}$ declining trends in various regions. By 2019, the emission reduction contributes about $47 \%$ of the $\mathrm{PM}_{2.5}$ decrease from 2013 to 2019 on the national average, while in the BTH region the emission reduction contributes more than $50 \%$, and in the YRD, PRD, and SWC regions, the contributions were between $32 \%$ and $37 \%$. For most of the regions, the emission reduction trend was consistent throughout the period except for FWP, NEC, SWC, and NWC, where the emission amounts were increased for certain years. The contribution by the meteorology to the surface $\mathrm{PM}_{2.5}$ concentrations from 2013 to 2019 was not found to show a consistent trend, fluctuating positively or negatively about $5 \%$ on the annual average and $10 \%-20 \%$ for the fall-winter heavy-pollution seasons. It is noted that the estimate of emission control contributions was made under a first-order approximation of emission and meteorology, which should be improved in the future implementations.

Code availability. This EMI system is now part of the official CMA operational forecasting framework and not publicly assessable. However, for research purposes, requests for the source code can be sent to the corresponding authors.

Data availability. The $\mathrm{PM}_{2.5}$ data are from the MEE (http:// english.mee.gov.cn, last access: 31 December 2020) and the meteorological data are from the CMA (http://www.cma.gov.cn/en2014/, last access: 31 December 2020). We have no authority to redistribute the data.
Author contributions. SG proposed the EMI concept and led the research project, and HL implemented the EMI concept in the modeling system. BZ and HZ led the operational implementation in the national center and provided the meteorological observational data. YW, JH and LZ led the modeling activities and result analysis. SW provided the emission change data and JW provided the observational data of pollutants.

Competing interests. The authors declare that they have no conflict of interest.

Acknowledgements. This work was supported by the National Natural Science Foundation of China (nos. 91744209, 91544232, and 41705080) and the Science and Technology Development Fund of the Chinese Academy of Meteorological Sciences (no. 2019Z009).

Financial support. This research has been supported by the National Natural Science Foundation of China (grant nos. 91744209, 91544232, and 41705080) and the Science and Technology Development Fund of the Chinese Academy of Meteorological Sciences (grant no. 2019Z009)

Review statement. This paper was edited by Joshua Fu and reviewed by Kun Luo and two anonymous referees.

\section{References}

Andersson, C., Langner, J., and Bergstroumm, R.: Interannual variation and trends in air pollution over Europe due to climate variability during 1958-2001 simulated with a regional CTM coupled to the ERA40 reanalysis, Tellus B, 59, 77-98, https://doi.org/10.1111/j.1600-0889.2006.00231.x, 2007.

Bai, H.-M., Shi, H.-D., Gao, Q.-X., Li, X.-C., Di, R.-Q., and Wu, Y.-H.: Re-Ordination of Air Pollution Indices of Some Typical Cities in Beijing-Tianjin-Hebei Region Based on Meteorological Adjustment, J. Ecol. Rural Environ., 31, 44-49, 2015.

Beaver, S. and Palazoglu, A.: Cluster Analysis of Hourly Wind Measurements to Reveal Synoptic Regimes Affecting Air Quality, J. Appl. Meteorol. Clim., 45, 1710-1726, 2006.

Bei, N. F., Li, X. P., Tie, X. X., Zhao, L. N., Wu, J. R., Li, X., Liu, L., Shen, Z. X., and Li, G. H.: Impact of synoptic patterns and meteorological elements on the wintertime haze in the Beijing-Tianjin-Hebei region, China from 2013 to 2017, Sci. Total Environ., 704, 135210, https://doi.org/10.1016/j.scitotenv.2019.135210, 2020.

Chang, L., Xu, J., Tie, X., and Wu, J.: Impact of the $2015 \mathrm{El}$ Nino event on winter air quality in China, Sci. Rep., 6, 34275, https://doi.org/10.1038/srep34275, 2016.

Chen, Y., Zhao, C. S., Zhang, Q., Deng, Z. Z., Huang, M. Y., and Ma, X. C.: Aircraft study of Mountain Chimney Effect of Beijing, China, J. Geophys. Res.-Atmos., 114, D08306, https://doi.org/10.1029/2008jd010610, 2009. 
Chen, Z., Chen, D., Kwan, M.-P., Chen, B., Gao, B., Zhuang, Y., $\mathrm{Li}, \mathrm{R}$., and $\mathrm{Xu}, \mathrm{B}$.: The control of anthropogenic emissions contributed to $80 \%$ of the decrease in $\mathrm{PM}_{2.5}$ concentrations in Beijing from 2013 to 2017, Atmos. Chem. Phys., 19, 13519-13533, https://doi.org/10.5194/acp-19-13519-2019, 2019.

Colette, A., Granier, C., Hodnebrog, Ø., Jakobs, H., Maurizi, A., Nyiri, A., Bessagnet, B., D'Angiola, A., D'Isidoro, M., Gauss, M., Meleux, F., Memmesheimer, M., Mieville, A., Rouïl, L., Russo, F., Solberg, S., Stordal, F., and Tampieri, F.: Air quality trends in Europe over the past decade: a first multimodel assessment, Atmos. Chem. Phys., 11, 11657-11678, https://doi.org/10.5194/acp-11-11657-2011, 2011.

Gong, S. L. and Zhang, X. Y.: CUACE/Dust - an integrated system of observation and modeling systems for operational dust forecasting in Asia, Atmos. Chem. Phys., 8, 2333-2340, https://doi.org/10.5194/acp-8-2333-2008, 2008.

Gong, S. L., Barrie, L. A., Blanchet, J.-P., Salzen, K. V., Lohmann, U., Lesins, G., Spacek, L., Zhang, L. M., Girard, E., Lin, H., Leaitch, R., Leighton, H., Chylek, P., and Huang, P.: Canadian Aerosol Module: A size-segregated simulation of atmospheric aerosol processes for climate and air quality models 1. Module development, J. Geophys. Res., 108, 4007, https://doi.org/10.1029/2001JD002002, 2003.

He, J. J., Yu, Y., Xie, Y. C., Mao, H. J., Wu, L., Liu, N., and Zhao, S. P.: Numerical Model-Based Artificial Neural Network Model and Its Application for Quantifying Impact Factors of Urban Air Quality, Water Air Soil Poll., 227, 235, https://doi.org/10.1007/s11270-016-2930-z, 2016.

He, J. J., Gong, S. L., Liu, H. L., An, X. Q., Yu, Y., Zhao, S. P., Wu, L., Song, C. B., Zhou, C. H., Wang, J., Yin, C. M., and Yu, L. J.: Influences of Meteorological Conditions on Interannual Variations of Particulate Matter Pollution during Winter in the Beijing-Tianjin-Hebei Area, J. Meteorol. Res., 31, 1062-1069, https://doi.org/10.1007/s13351-017-7039-9, 2017a.

He, J. J., Gong, S. L., Yu, Y., Yu, L. J., Wu, L., Mao, H. J., Song, C. B., Zhao, S. P., Liu, H. L., Li, X. Y., and Li, R. P.: Air pollution characteristics and their relation to meteorological conditions during 2014-2015 in major Chinese cities, Environ. Pollut., 223, 484-496, https://doi.org/10.1016/j.envpol.2017.01.050, $2017 \mathrm{~b}$.

He, J. J., Gong, S. L., Zhou, C. H., Lu, S. H., Wu, L., Chen, Y., Yu, Y., Zhao, S. P., Yu, L. J., and Yin, C. M.: Analyses of winter circulation types and their impacts on haze pollution in Beijing, Atmos. Environ., 192, 94-103, https://doi.org/10.1016/j.atmosenv.2018.08.060, 2018.

Hou, X. W., Zhu, B., Kumar, K. R., and Lu, W.: Inter-annual variability in fine particulate matter pollution over China during 2013-2018: Role of meteorology, Atmos. Environ., 214, 116842, https://doi.org/10.1016/j.atmosenv.2019.116842, 2019.

Li, X., Zhang, Q., Zhang, Y., Zheng, B., Wang, K., Chen, Y., Wallington, T. J., Han, W., Shen, W., Zhang, X., and He, K.: Source contributions of urban $\mathrm{PM}_{2.5}$ in the Beijing-TianjinHebei region: Changes between 2006 and 2013 and relative impacts of emissions and meteorology, Atmos. Environ., 123, 229239,2015

Liu, T., Gong, S., He, J., Yu, M., Wang, Q., Li, H., Liu, W., Zhang, J., Li, L., Wang, X., Li, S., Lu, Y., Du, H., Wang, Y., Zhou, C., Liu, H., and Zhao, Q.: Attributions of meteorological and emission factors to the 2015 winter severe haze pollution episodes in
China's Jing-Jin-Ji area, Atmos. Chem. Phys., 17, 2971-2980, https://doi.org/10.5194/acp-17-2971-2017, 2017.

Ma, T., Duan, F. K., He, K. B., Qin, Y., Tong, D., Geng, G. N., Liu, X. Y., Li, H., Yang, S., Ye, S. Q., Xu, B. Y., Zhang, Q., and Ma, Y. L.: Air pollution characteristics and their relationship with emissions and meteorology in the Yangtze River Delta region during 2014-2016, J. Environ. Sci., 83, 8-20, https://doi.org/10.1016/j.jes.2019.02.031, 2019.

MEE: Ambient air quality standards: GB 3095-2012, China Environmental Science Press, Beijing, China, 2012.

Nenes, A., Pandis, S. N., and Pilinis, C.: ISORROPIA: A new thermodynamic equilibrium model for multiphase multicomponent inorganic aerosols, Aquat. Geochem., 4, 123-152, 1998.

Niu, T., Gong, S. L., Zhu, G. F., Liu, H. L., Hu, X. Q., Zhou, C. H., and Wang, Y. Q.: Data assimilation of dust aerosol observations for the CUACE/dust forecasting system, Atmos. Chem. Phys., 8, 3473-3482, https://doi.org/10.5194/acp-8-3473-2008, 2008.

Pearce, J. L., Beringer, J., Nicholls, N., Hyndman, R. J., and Tapper, N. J.: Quantifying the influence of local meteorology on air quality using generalized additive models, Atmos. Environ., 45, 1328-1336, https://doi.org/10.1016/j.atmosenv.2010.11.051, $2011 \mathrm{a}$.

Pearce, J. L., Beringer, J., Nicholls, N., Hyndman, R. J., Uotila, P., and Tapper, N. J.: Investigating the influence of synopticscale meteorology on air quality using self-organizing maps and generalized additive modelling, Atmos. Environ., 45, 128-136, https://doi.org/10.1016/j.atmosenv.2010.09.032, 2011 b.

Stockwell, W. R., Middleton, P., Change, J. S., and Tang, X.: The second generation Regional Acid Deposition Model Chemical Mechanizm for Regional Ai Quality Modeling, J. Geophy. Res., 95, 16343-16376, 1990.

Wang, S., Xing, J., Chatani, S., Hao, J., Klimont, Z., Cofala, J., and Amann, M.: Verification of anthropogenic emissions of China by satellite and ground observations, Atmos. Environ., 45, 63476358, 2011.

Wei, Y., Li, J., Wang, Z.-F., Chen, H.-S., Wu, Q.-Z., Li, J.-J., Wang, Y.-L., and Wang, W.: Trends of surface $\mathrm{PM}_{2.5}$ over BeijingTianjin-Hebei in 2013-2015 and their causes: emission controls vs. meteorological conditions, Atmos. Ocean. Sci. Lett., 10, 276 283, 2017.

Wu, D., Chen, H. Z., Meng, W. U., Liao, B. T., Wang, Y. C., Liao, X. N., Zhang, X. L., Quan, J. N., Liu, W. D., and Yue, G. U.: Comparison of three statistical methods on calculating haze daystaking areas around the capital for example, China Environ. Sci., 34, 545-554, 2014.

Xu, X., Zhou, M., Chen, J., Bian, L., Zhang, G., Liu, H., Li, S., Zhang, H., Zhao, Y., Suolongduoji, and Jizhi, W.: A comprehensive physical pattern of land-air dynamic and thermal structure on the Qinghai-Xizang Plateau, Sci. China Ser. D-Earth Sci., 45, 577-594, 2002.

Xu, X. D., Wang, Y. J., Zhao, T. L., Cheng, X. H., Meng, Y. Y., and Ding, G. A.: "Harbor" effect of large topography on haze distribution in eastern China and its climate modulation on decadal variations in haze China, Chin. Sci. Bull., 60, 1132-1143, 2015.

Yu, Y., He, J. J., Zhao, S. P., Liu, N., Chen, J. B., Mao, H. J., and $\mathrm{Wu}, \mathrm{L} .:$ Numerical simulation of the impact of reforestation on winter meteorology and environment in a semi-arid urban valley, Northwestern China, Sci. Total Environ., 569, 404-415, https://doi.org/10.1016/j.scitotenv.2016.06.143, 2016. 
Zhang, H., Zhang, B., Lu, M., and An, L.: Developmenot and Application of Stable Weather Index of Beijing in Environmental Meteorology, Meteorol. Month., 43, 998-1004, 2017.

Zhang, Q. and Rao, C.: A Comparative Study of $\mathrm{PM}_{2.5}$ in Typical Cities after the Standard Conditions Turn to Actual Conditions, Energ. Conserv. Environ. Protect., 6, 79-80, 2019.

Zhao, B., Wu, W., Wang, S., Xing, J., Chang, X., Liou, K.-N., Jiang, J. H., Gu, Y., Jang, C., Fu, J. S., Zhu, Y., Wang, J., Lin, Y., and Hao, J.: A modeling study of the nonlinear response of fine particles to air pollutant emissions in the BeijingTianjin-Hebei region, Atmos. Chem. Phys., 17, 12031-12050, https://doi.org/10.5194/acp-17-12031-2017, 2017.

Zheng, H., Zhao, B., Wang, S., Wang, T., Ding, D., Chang, X., Liu, K., Xing, J., Dong, Z., Aunan, K., Liu, T., Wu, X., Zhang, S., and Wu, Y.: Transition in source contributions of $\mathrm{PM}_{2.5}$ exposure and associated premature mortality in China during 2005-2015, Environ. Int., 132, 105111, https://doi.org/10.1016/j.envint.2019.105111, 2019.
Zhou, C., Gong, S., Zhang, X., Liu, H., Xue, M., Cao, G., An, X., Che, H., Zhang, Y., and Niu, T.: Towards the improvements of simulating the chemical and optical properties of Chinese aerosols using an online coupled model - CUACE/Aero, Tellus B, 64, 91-102, https://doi.org/10.3402/tellusb.v64i0.18965, 2012.

Zhou, Z., Zhang, S., Gao, Q., Li, W., Zhao, L., Feng, Y., Xu, M., and Shi, L.: The Impact of Meteorological Factors on Air Quality in the Beijing-Tianjin-Hebei Region and Trend Analysis, Resour. Sci., 36, 191-199, 2014. 